\title{
PENGEMBANGAN APLIKASI MOBILE AUGMENTED REALITY UNTUK MENDUKUNG PENGENALAN KOLEKSI MUSEUM
}

\author{
Komang Candra Brata ${ }^{1}$, Adam Hendra Brata ${ }^{2}$, Yudha Akbar Pramana ${ }^{3}$ \\ ${ }^{1,2,3}$ Fakultas Ilmu Komputer Universitas \\ Email: ${ }^{1}$ k.candra.brata@ub.ac.id, ${ }^{2}$ adam@ub.ac.id, ${ }^{3}$ akbaryu@gmail.com
}

(Naskah masuk: 2 Mei 2018, diterima untuk diterbitkan: 09 Agustus 2018)

\begin{abstract}
Abstrak
Museum merupakan tempat yang didalamnya terdapat benda-benda warisan budaya yang dapat digunakan untuk menambah wawasan dan pengetahuan terkait sejarah di masa lalu. Namun pada kenyataannya, banyak benda bersejarah di museum yang rusak akibat dari kelalaian pengunjung dan pihak pengelola museum. Augmented Reality (AR) merupakan teknologi yang berkembang dan sangat diminati saat ini sehingga menawarkan peluang baru sebagai media alternative pengenalan benda-benda di museum. Penelitian ini bertujuan untuk mengimplementasikan teknologi AR untuk mengenalkan benda-benda museum sehingga terlihat interaktif bagi pengunjung serta dapat mengurangi resiko kerusakan benda di museum. Dengan dikembangkannya aplikasi ini, diharapkan mampu meminmalisir jumlah benda-benda yang rusak karena kelalaian pengunjung serta dengan adanya sistem yang interaktif dapat meningkatkan minat masyarakat untuk mengunjungi musium sebagai salah satu tempat untuk mengenal dan menambah informasi terkait warisan budaya dan sejarah. Aplikasi ini dikembangkan dengan mengadopsi Agile proses untuk lebih mudah mengakomodasi perubahan. Hasil pengujian fungsionalitas setelah aplikasi diimplementasikan menunjukan bahwa semua kebutuhan fungsional telah terpenuhi oleh sistem dan dapat digunakan sesuai dengan kebutuhan. Hasil pengujian juga menunjukkan bahwa semua fitur aplikasi dapat dijalankan dengan baik di berbagai versi platform Android. Hasil dari pengujian usabilitas aplikasi dengan memberikan kuesioner System Usability Scale (SUS) kepada pengunjung museum dan staf museum, menunjukkan angka kepuasan pengunjung sebesar 86\%. Dari nilai tersebut dapat disimpulkan bahwa aplikasi ini dapat dengan mudah digunakan untuk membantu pengenalan benda koleksi museum.
\end{abstract}

Kata kunci: museum, android, augmented reality, agile, system usability scale.

\section{DEVELOPMENT OF A MOBILE AUGMENTED REALITY APPLICATION FOR SUPPORTING THE MUSEUM COLLECTION RECOGNITION}

\begin{abstract}
Museum is a place that contain various objects of cultural heritage that can lead to gain new insight and knowledge for young generations. However, there are many cases that many museum's objects are damaged by museum visitors. Augmented Reality (AR) is an emerging technology that offer new possibilities as an alternative media to display museum collections to visitors. This work aim to develop an augmented reality application to introduce museum collections in more interesting ways for visitors and also to mitigate the risk about damaged museum collections by careless visitors. This application was developed using Agile software development process. Functional testing of proposed application shows that all functional requirements have been met by the system. Additionally, testing results indicate that all application features can be well executed in various version of Android. The result of usability testing by giving questionnaires of System Usability Scale (SUS) to the respondents of museum visitors and museum staf, obtaining visitor satisfaction result gets $86 \%$ of museum staf satisfaction toward application. From these values can be concluded that this application can help the introduction of museum objects to museum visitors. Compatibility testing indicates that the work validity of these features can be well executed.
\end{abstract}

Keywords: museum, android, augmented reality, agile, system usability scale. 


\section{PENDAHULUAN}

Indonesia sangat banyak memiliki peninggalan kebudayaan dan sejarah yang dapat dibanggakan. Salah satu sarana yang dapat digunakan untuk mewariskan informasi sejarah dan budaya tersebut ke generasi penerus bangsa adalah musem. Museum adalah salah satu objek wisata untuk menambah wawasan dan pengetahuan yang didalamnya terdapat benda-benda warisan budaya masa lalu. Museum bertugas mengumpulkan, mendata, merawat, dan memamerkan koleksi untuk tujuan wawasan, pengetahuan, pendidikan, dan sumber penelitian bagi masyarakat umum (Direktorat Museum, 2009).

Dari studi literatur, ditemukan fakta bahwa banyak kasus rusaknya benda koleksi museum oleh pengunjung yang ceroboh dalam memegang benda tersebut (Calsen, 2006). Hal ini tentu berdampak pada berkurangnya koleksi menarik di museum yang berdampak pada turunnya minat kunjungan ke museum. Menurut Jean (Tribun-Maluku, 2017:2) turunnya minat pengunjung menjadikan tantangan bagi pihaknya untuk lebih berinovasi dan berkreasi dengan ide-ide yang lebih kreatif.

Menurut data studi perbandingan pengguna antara Android dan iOS tahun 2017 oleh perusahaan teknologi Moon Technolabs Pvt Ltd. Android mendominasi pasar dengan prosentase sebesar $87 \%$, sementara iOS berada di posisi kedua dengan $12 \%$. Android memiliki pangsa pasar yang lebih banyak di negara berkembang seperti Asia dan Afrika sementara iOS memimpin pasar di negara maju seperti AS, Australia, Eropa, dll. Hal ini mungkin disebabkan oleh berbagai faktor budaya dan sosioekonomi yang dimainkan di wilayah geografis setempat (Technolabs, 2017).

Augmented Reality (AR) adalah teknologi yang dapat menggabungkan dunia nyata dengan dunia maya dalam bentuk 3D serta bersifat interaktif menurut waktu nyata (real time). Selain itu, AR merupakan teknologi yang berkembang dan sangat diminati saat ini. Teknologi AR bisa diimplementasikan ke dalam berbagai bidang antara lain pendidikan, hiburan, kesehatan, dan banyak lainnya (Azuma, 2001)(Craig, Alan B., 2013).

Berdasarkan pada permasalahan yang ditemukan, penelitian ini bertujuan untuk mengimplementasikan teknologi AR untuk mengenalkan benda-benda museum sehingga terlihat interaktif bagi pengunjung serta dapat mengurangi resiko kerusakan benda di museum. Dengan dikembangkannya aplikasi ini, diharapkan mampu meminmalisir jumlah benda-benda yang rusak karena kelalaian pengunjung serta dengan adanya sistem yang interaktif dapat meningkatkan minat masyarakat untuk mengunjungi musium sebagai salah satu tempat untuk mengenal dan menambah informasi terkait warisan budaya dan sejarah.

Penelitian ini mengambil studi kasus pada museum $\mathrm{Mpu}$ Purwa Malang dengan melibatkan langsung para pengunjung beserta staff museum untuk dijadikan sebagai data masukan untuk melakukan validasi sitem.

\section{METODOLOGI}

Metode yang digunakan dalam penelitian ini adalah model pengembangan sistem yang diadaptasi dari model Agile SDLC seperti pada gambar 1.

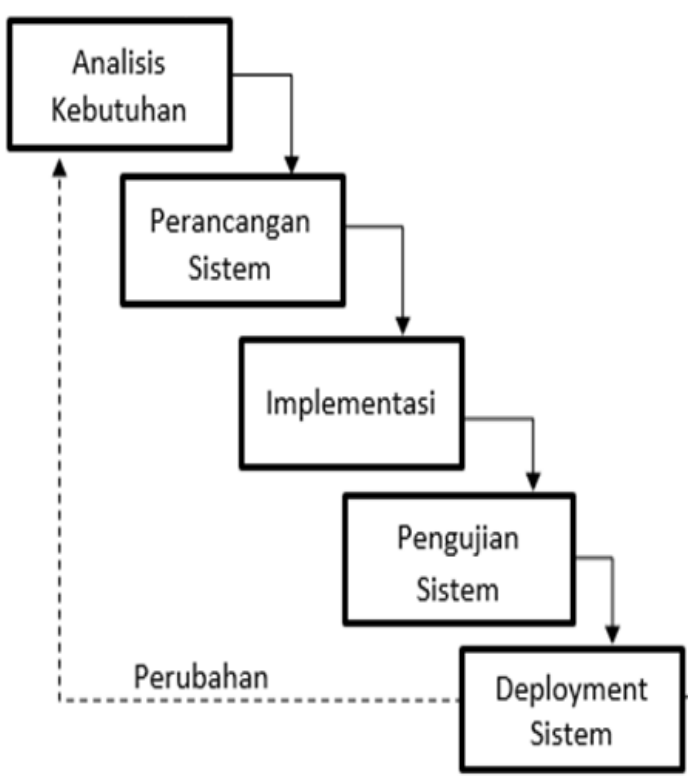

Gambar 1. Model pengembangan sistem adaptasi dari model Agile SDLC

Metode pengembangan Agile dipilih karena lebih fleksibel ketika mengakomodasi perubahan kebutuhan yang diberikan oleh pengguna (Cockburn,2001) (Pressman,2010).

\subsection{Analisis Kebutuhan}

Analisis kebutuhan dilakukan dengan cara melakukan observasi pada beberapa sample museum di Kota Malang, selain itu juga dilakukan wawancara kepada Staf Museum yang digunakan untuk menggali semua kebutuhan sistem perangkat lunak. Kemudian dimodelkan kedalam sebuah usecase diagram untuk memudahkan manajemen kebutuhan.

\subsection{Perancangan Sistem}

Pada tahap perancangan, akan dilakukan perancangan terkait perancangan objek untuk pembuatan marker serta perancangan struktur menu dari antar muka dengan tujuan agar memudahkan pengguna dalam bernavigasi di dalam aplikasi. 


\subsection{Implementasi}

Tahapan implementasi untuk mewujudkan konsep perancangan menjadi bentuk aplikasi yang akan siap untuk digunakan. Implementasi source code menggunakan bahasa pemrograman Java dengan Android Studio, Unity 3D, library Vuforia SDK, dan library ULSee SDK (Vuvoria,2018).

\subsection{Pengujian Sistem}

Pada tahapan pengujian dilakukan ketika proses dari implementasi sudah dilakukan. Pengujian dilakukan menggunakan metode Blackbox Testing (pengujian fungsional) dan pengujian nonfungsional (pengujian compatibility dan usability).

\subsection{Deployment Sistem}

Pada tahapan ini dimana sistem dibuat tersedia bagi pengunjung museum. Jika dalam deployment sistem terdapat kesalahan atau kekurangan pada sistem, maka dapat mengulang kembali ke tahap analisis untuk memperbaiki serta menambahkan kekurangan fungsi program. Pertama-tama sistem dikompilasi untuk dijadikan sebuah berkas installer Android dengan format berkas *.apk. Kemudian berkas installer ini diunggah ke GooglePlay agar dapat diunduh dan di-install atau dipasang pada perangkat smartphone pengunjung.

\section{HASIL DAN PEMBAHASAN}

Pada bagian ini akan membahas tentang analisis dan perancangan sistem, implementasi sistem, dan pengujian sistem dari aplikasi augmented reality yang menggunakan metode pengembangan sistem adaptasi dari model Agile SDLC.

\subsection{Analisis Kebutuhan}

Dari observasi dan wawancara dapat diketahui bahwa di dalam aplikasi ini terdapat dua aktor, yaitu diantaranya ada pengunjung dan staf Museum.

\begin{tabular}{cl}
\multicolumn{1}{c}{ Tabel 1. Identifikasi Aktor } \\
\hline Pktor & \multicolumn{1}{c}{ Deskripsi } \\
\hline Pengunjung & $\begin{array}{l}\text { Pengunjung adalah semua orang yang } \\
\text { menggunakan aplikasi. Pengunjung } \\
\text { menggunakan aplikasi untuk membaca }\end{array}$ \\
& informasi museum, membaca tentang benda \\
& dalam museum, melihat objek 3D benda \\
& museum menggunakan Face Masks \\
& Augmented Reality, dan melihat objek 3D \\
& benda-benda pada leaflet menggunakan \\
& Marker Augmented Reality. \\
& $\begin{array}{l}\text { Staf Museum adalah orang yang mengelola } \\
\text { data informasi museum dan informasi } \\
\text { benda museum. }\end{array}$ \\
\hline
\end{tabular}

Dari proses observasi dan wawancara dapat diketahui kebutuhan fungsional dan non fungsional pada perangkat aplikasi ini. Untuk mengetahui kebutuhan fungsional pada aplikasi ini maka dibuatkan use case diagram yang dapat dilihat pada Gambar 2.

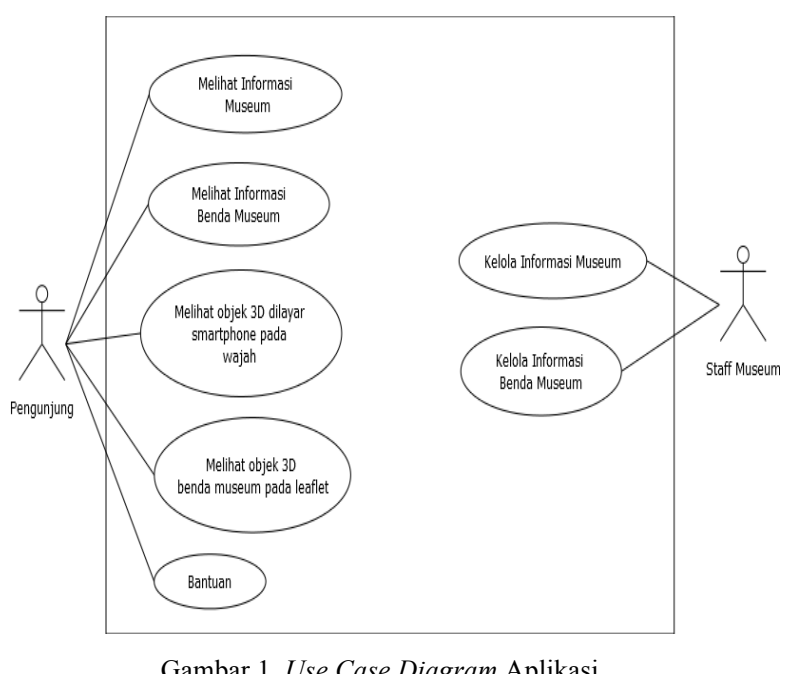

Untuk Pengguna, aplikasi dapat memberikan informasi tentang museum serta benda-benda museum, memberikan layanan augmented reality pada wajah dengan menampilkan objek 3D benda yang bersifat dipakai pada wajah, dan memberikan layanan augmented reality dengan menampilkan objek 3D benda pada leaflet/brosur kunjungan. Aplikasi ini juga telah diintegrasikan dengan sistem admin yang dapat digunakan oleh staf museum untuk mengelola data informasi museum maupun benda koleksi museum.

\subsection{Perancangan}

Perancangan sistem yang akan dijalankan terdiri dari : perancangan marker, pembuatan objek 3D untuk FaceAR, pembuatan objek 3D untuk LeafletAR. Pada Tahap ini dilakukan pemodelan objeck 3D yang representatif dengan objek asli benda benda di museum. Proses pemodelan dapat dilihat pada Gambar 3.

Perancangan struktur mеnu menampilkan berbagai menu yang tersedia pada aplikasi. Semua menu yang ada pada aplikasi digambarkan dalam bentuk hirarki. Tiap-tiap тепи terhubung melalui garis yang menyatakan adanya hubungan dari satu тепи ke тепи yang lainnya. Perancangan struktur menu pada aplikasi ini dapat dilihat pada Gambar 4.

Setelah тепи utama terdapat beberapa тепи yang dapat dipilih oleh pengunjung yaitu Informasi Museum, Informasi Benda Museum, FaceAR Benda Museum, dan AR Leaflet Museum. Didalam Informasi Museum berisi informasi tentang kilas sejarah Museum. Didalam informasi benda museum berisi tentang informasi benda-benda yang ada didalam Museum. Didalam menu ObjectAR terdapat Algoritme pendeteksian marker yang dapat dipasang pada leaflet/bahkan langsung pada bendanya sehingga waktu user mengarahkan kamera smartphone pada objek yang sesuai akan muncul 
objek AR sesuai yang terdeteksi. Didalam FaceAR terdapat algoritme pendeteksian wajah yang nantinya akan digunakan untuk menampilakn objek AR menikuti wajah dari pengguna. Menu Bantuan berisi informasi tentang kegunaan tombol dan cara menggunakan aplikasi.

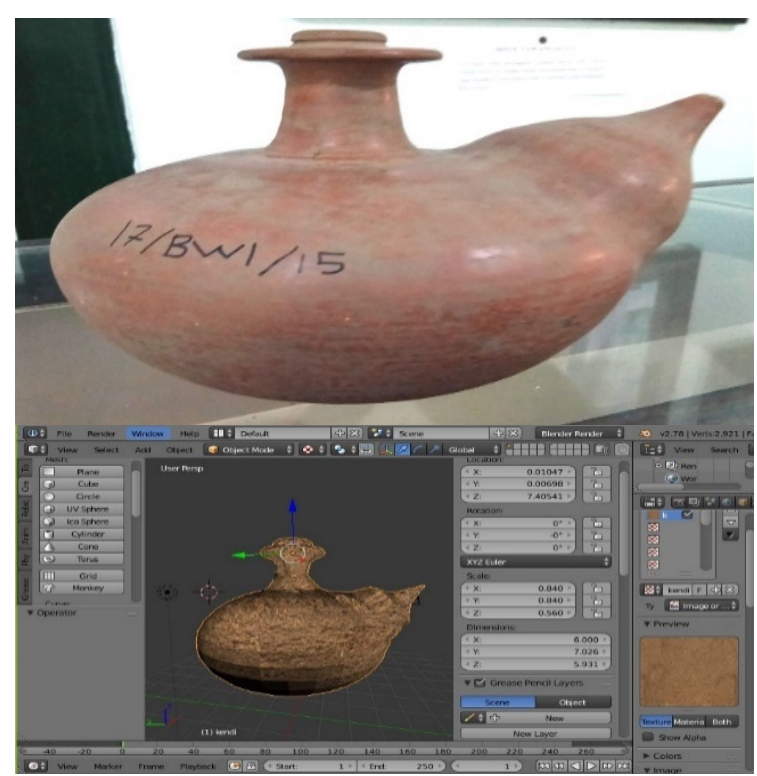

Gambar 3. Pemodelan kendi susu

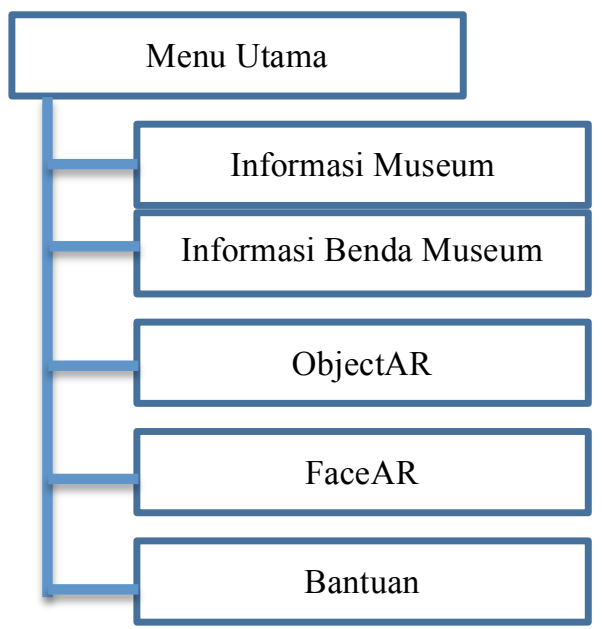

Gambar 4. Rancangan struktur menú dari antarmuka aplikasi

\subsection{Implementasi}

Pada tahap implementasi akan dijelaskan hasil implementasi objek 3D, implementasi marker, serta implementasi antarmuka aplikasi yang telah dirancang untuk memenuhi kebutuhan pengguna.

\subsubsection{Halaman ObjectAR Museum}

Pada tahap ini obyek 3D yang dibuat adalah obyek dari benda koleksi museum yang sering dilihat dan berinteraksi langsung dengan pengunjung. Pada menu ini pengunjung dapat menggunakan fitur augmented reality untuk berfoto dengan objek 3D museum yang ditampilkan pada leaflet/brosur. Gambar marker didapat dengan cara men-scan leaflet/brosur kunjungan museum. Gambar leaflet ini digunakan sebagai marker untuk augmented reality. Leaflet ini memiliki informasi berupa gambar dan keterangan terkait benda-benda museum yang ditampilkan. Implementasi detail dapat dilihat pada pada gambar 5 .

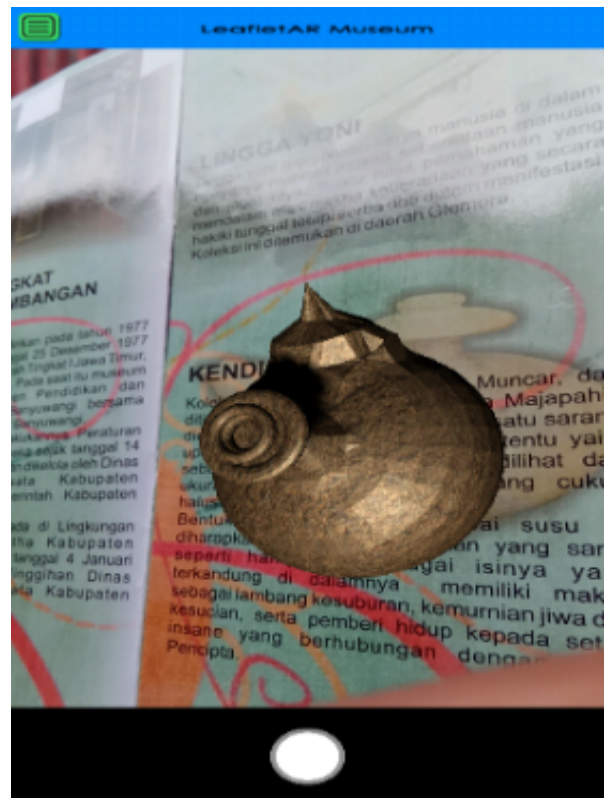

Gambar 5. Impementasi Objek 3D untuk ObjectAR

\subsubsection{Halaman Face AR Museum}

Gambar 6 merupakan tampilan halaman FaceAR museum. Pada halaman ini pengunjung dapat menggunakan fitur augmented reality untuk berfoto dengan objek 3D museum yang dapat dipakai di kepala seperti udeng, topeng dan lain sebagainya.

\subsection{Pengujian}

Pengujian perangkat lunak dapat dilakukan dengan metode pengujian Blackbox Testing (pengujian fungsional) dan pengujian nonfungsional (pengujian compatibility, dan pengujian usability) (Naik, 2008). Pengujian Blackbox dilakukan untuk mengetahui aplikasi yang dibuat sudah berjalan dengan baik dan benar dan dapat digunakan oleh orang lain. Pengujian ini juga sekaligus bertujuan untuk menguji kompabilitas sistem terhadap beragamnya sistem operasi Android yang dipakai pada smartphone pengguna. Pengujian dilakukan oleh 5 penggguna yang dipilih secara acak 
yang semuanya menggunakan smartphone yang berbeda versi sistem operasi android yaitu versi 4.3, versi 5.1, dan versi 6.0. Berdasarkan hasil pengujian pada kasus uji kebenaran proses, bahwa semua fitur di dalam aplikasi dari mulai pertama dijalankan sampai dengan selesai menyelesaikan tugas dapat berfungsi dengan baik sesuai dengan kebutuhan.

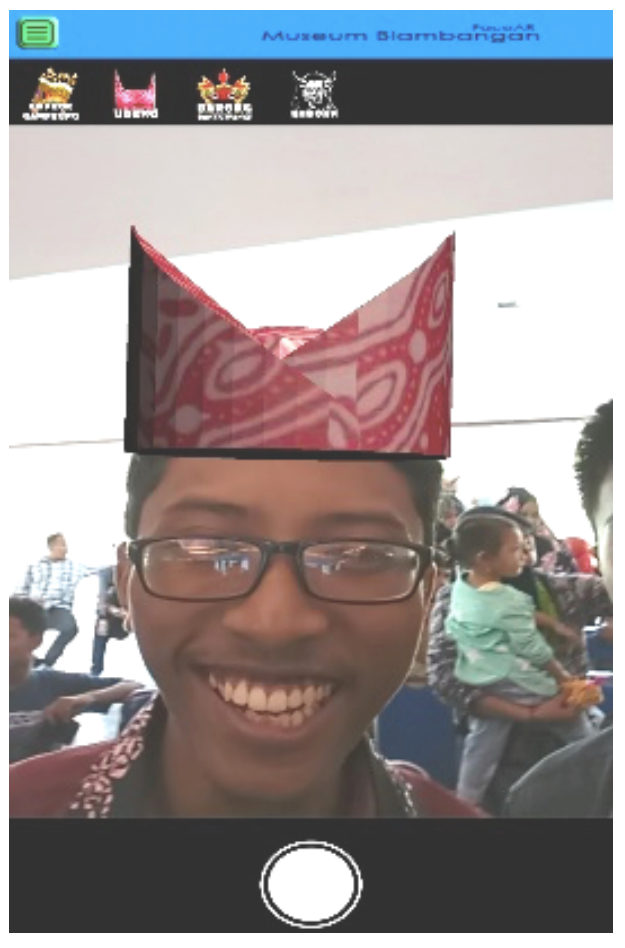

Gambar 6. Halaman FaceAR Museum

Pengujian usability bertujuan untuk melihat seberapa kemudahan penggunaan aplikasi oleh pengunjung dan staf museum. Pengujian dijalankan dengan menggunakan SUS (System Usability Scale kuesioner yang terdiri dari 10 pertanyaan serta pilihan jawaban dengan nilai $0-4$ yang dimulai dari sangat tidak setuju (STS), tidak setuju (TS), netral (N), setuju (S) serta sampai sangat setuju(SS) pada masing-masing pertanyaan (Lewis, 2009).

Kuesioner yang dibagikan kepada 20 responden yang terdiri dari pengunjung dan staf. Jumlah responden yang digunakan pada pengujian fungsional dan pengujian usability diambil berdasarkan data dari Nielsen yang menyatakan jumlah tersebut sudah lebih dari batas minimal untuk melakukan pengujian secara efektif dan efisien (Nielsen, 2017). Hasil dari pengujian usabilitas dapat dilihat pada Tabel 2. Dari hasil kuisioner, didapatkan rata-rata nilai SUS sebesar 86 yang berarti termasuk dalam klasifikasi diatas rata-rata (Sauro, 2011 ).

\section{KESIMPULAN}

Berdasarkan pengembangan perangkat lunak yang telah dilakukan, dapat diambil kesimpulan bahwa aplikasi Augmented Reality untuk pengenalan benda di museum berbasis Android telah sesuai dengan analisis kebutuhan yaitu terdapat 5 kebutuhan untuk pengunjung dan 2 kebutuhan untuk staf.

Berdasarkan pengujian fungsional, semua fitur yang ada pada aplikasi dapat berjalan dengan baik sesuai dengan kebutuhan di berbagai versi sistem operasi Android yaitu versi 4.3, versi 5.1, dan versi 6.0. Pengujian usability melalui kuesioner yang telah diberkan kepada pengunjung dan staf museum menghasilkan kesimpulan bahwa kepuasan pengunjung mendapat angka $86 \%$, yang artinya bahwa aplikasi ini dapat membantu pengenalan benda di museum oleh pengunjung dan staf museum.

\begin{tabular}{|c|c|c|}
\hline No & Kuesioner & Total \\
\hline 1 & $\begin{array}{l}\text { Saya akan sering menggunakan } \\
\text { aplikasi ini. }\end{array}$ & 65 \\
\hline 2 & $\begin{array}{l}\text { Saya merasa aplikasi ini tidak perlu } \\
\text { rumit. }\end{array}$ & 72 \\
\hline 3 & $\begin{array}{l}\text { Saya pikir aplikasi ini mudah } \\
\text { digunakan. }\end{array}$ & 65 \\
\hline 4 & $\begin{array}{l}\text { Saya merasa memerlukan dukungan } \\
\text { dari orang teknis untuk dapat } \\
\text { menggunakan aplikasi ini. }\end{array}$ & 69 \\
\hline 5 & $\begin{array}{l}\text { Saya merasa jika fungsi dalam } \\
\text { aplikasi ini sudah terintegrasi dengan } \\
\text { baik. }\end{array}$ & 68 \\
\hline 6 & $\begin{array}{l}\text { Saya menemukan ketidak } \\
\text { konsistenan dalam aplikasi ini. }\end{array}$ & 66 \\
\hline 7 & $\begin{array}{l}\text { Saya rasa cara menggunakan aplikasi } \\
\text { ini mudah dipelajari. }\end{array}$ & 70 \\
\hline 8 & $\begin{array}{l}\text { Saya merasa aplikasi ini sangat rumit } \\
\text { untuk digunakan. }\end{array}$ & 70 \\
\hline 9 & $\begin{array}{l}\text { Saya merasa sangat percaya diri } \\
\text { ketika menggunakan aplikasi ini. }\end{array}$ & 67 \\
\hline 10 & $\begin{array}{l}\text { Saya perlu belajar banyak hal } \\
\text { sebelum saya bisa menggunakan } \\
\text { aplikasi ini. }\end{array}$ & 76 \\
\hline \multicolumn{2}{|c|}{ Jumlah nilai total $* 2.5$} & 1720 \\
\hline \multicolumn{2}{|c|}{ Rata-rata skor tiap responden } & 86 \\
\hline
\end{tabular}

\section{DAFTAR PUSTAKA}

AZUMA, R., BAILLOT, Y., BEHRINGER, R., FEINER, S., JULIER, S., \& MACINTYRE, B. 2001. Recent advances in augmented reality. NAVAL RESEARCH LAB WASHINGTON DC.

CLASSEN, C., \& HOWES, D. 2006. The museum as sensescape: Western sensibilities and indigenous artifacts. Sensible objects: Colonialism, museums and material culture, 5, 199.

COCKBURN, A., \& HIGHSMITH, J. 2001. Agile software development, the people factor. Computer, 34(11), 131-133.

CRAIG, A. B. 2013. Understanding augmented reality: Concepts and applications. Newnes. 
DIREKTORAT MUSEUM. 2009. Ayo Kita Mengenal Museum. Jakarta. Departemen Kebudayaan dan Pariwisata

LEWIS, JAMES R., dan JEFF SAURO. 2009."The factor structure of the system usability scale." International conference on human centered design. Springer, Berlin, Heidelberg.

NAIK, K. DAN TRIPATHY, P. 2008. Software Testing and Quality Assurance Theory and Practice. Canada : Wiley

NIELSEN J. 2017. "Usability 101: introduction to usability“. [Online]. Tersedia di: http://www.nngroup.com/articles/u sability-101-introductionto-usability [Diakses, 10 Januari 2017]

PRESSMAN, ROGER S. 2010. Software Engineering: A Practitioner's Approach S.

SAURO, JEFF. 2011. A practical guide to the system usability scale: Background, benchmarks \& best practices. Measuring Usability LLC.

TECHNOLABS. 2017. Apple Vs Android - A comparative study 2017. [online] Tersedia di: https://android.jlelse.eu/apple-vsandroid-a-comparative-study-2017c5799a0a1683 [Diakses 21 Mei 2017]

TRIBUN-MALUKU. 2017. Minat belajar SMA ke museum siwalima menurun. [online] Tersedia di: http://www.tribunmaluku.com/2017/0/minat-pelajar-sma-kemuseum-siwalima- menurun.html,tribunmaluku,hal.2. [diakses 26 Mei 2017]

VUVORIA. 2018. Vovoria developer SDK. [Online] Tersedia di:

https://developer.vuforia.com/downloads/sd k [Diakses, 10 Januari 2018] 